\title{
TRABALHO FEMININO NA CAFEICULTURA DO MUNICÍPIO DE DIVISA NOVA-MG: UMA ANÁLISE SOBRE AS ANTIGAS E ATUAIS APANHADORAS DE CAFÉ
}

\author{
Glaucione RAIMUNDO' \\ Ana Rute do VALE ${ }^{2}$
}

\section{Resumo}

Estudos de gênero na Geografia iniciaram-se, no Brasil, pós-década de 1970, a partir de análises de divisões de trabalhos por sexo, idade, e relações de poder familiar, passando a incluir também nessas discussões as mulheres no campo, até então eram marginalizadas. A partir daí a mulher passa a ser retratada como um ator social, detentora papéis produtivos e reprodutivos. É nesse contexto que esse estudo se propôs a analisar o papel das trabalhadoras sazonais na cafeicultura ("apanhadoras de café") do município de Divisa Nova, na mesorregião Sul/Sudoeste de Minas Gerais. O objetivo principal foi analisar o papel de antigas e novas gerações dessas trabalhadoras, sobretudo no que se refere às conquistas trabalhistas, a participação delas na renda familiar e os motivos pelos quais as mais jovens estão trocando os cafezais pelos empregos urbanos. A partir daí, buscou-se apontar o "possível" futuro das apanhadoras de café do município.

Palavras-chave: Geografia. Gênero. Mulher. Café. Trabalho.

\section{Abstract \\ Feminine work in the coffee crop of the municipality of Divisa Nova-MG: an analysis of old and current coffee takers}

Gender studies in geography began im Brazil in the post-1970s, based on analyzes of division of labor by sex, age, and family power relations, and also taking into account in these discussions the rural women, who were marginalized until then. From then on woman happens to be portrayed as a social actor, holding productive and reproductive roles. It is in this context that this study aims to analyze the role of seasonal workers in coffee cultivation ("coffee pickers") at the municipality of Divisa Nova, in the South / Southwest mesoregion of Minas Gerais. The main purpose was to analyze the role of former and new generations of these workers, especially with regard to the labor achievements, their participation in the family income and the reasons why the younger women are switching from the coffee plantations to the urban jobs. From that point, it was sought to identify the "possible" future of the coffee pickers in the city.

Key words: Geography. Gender. Woman. Coffee. Work.

\footnotetext{
${ }^{1}$ Graduada em Geografia Licenciatura - UNIFAL-MG. E-mail: glaucioneprado@yahoo.com.br

2 Docente do curso de Geografia - UNIFAL-MG. E-mail: ana.vale@unifal-mg.edu.br
} 


\section{INTRODUÇÃO}

O trabalho da mulher quer seja em áreas urbanas ou rurais, é visto sobre perspectivas que as incapacitam e as desvalorizam. O trabalho masculino, por sua vez, se sobrepõe em relações as atividades desenvolvidas por elas. Invisibilidade social, dupla jornada de trabalho, salários inferiores e julgamentos estereotipados são algumas das dificuldades encontradas por elas, no seu ambiente de trabalho. No caso das mulheres que trabalham na colheita de café - as "apanhadora de café" - em Minas Gerais, a situação não é diferente, como foi observado no município de Divisa Nova, tomado como estudo de caso nesse trabalho. A presença das mulheres nesse tipo de atividade sempre foi muito importante no município, mas vem diminuindo nos últimos anos, por conta pela mecanização nos cafezais e as novas oportunidades de emprego em áreas urbanas, com a instalação de algumas fábricas têxteis na cidade.

Sendo predominantemente agrícola e voltado, sobretudo, para a monocultura além do café, também vem se expandindo a produção de cana-de-açúcar -, Divisa Nova caracteriza-se como um município dominado pelo agronegócio que, em geral, baseia-se em elevada concentração fundiária e mecanização agrícola. Consequentemente, o processo de êxodo rural e de urbanização, tornaram-se realidade no município, com pouca oportunidade de empregos na zona urbana também.

Nesse sentido, a pesquisa analisou o trabalho sazonal realizado por mulheres em colheitas de café no município de Divisa Nova -MG, de modo a demonstrar o papel de antigas e novas gerações dessas trabalhadoras, sobretudo no que se refere às conquistas trabalhistas, a participação delas na renda familiar e os motivos pelos quais as mais jovens estão abandonando essa atividade e buscando postos de trabaIho urbanos. A partir daí, apontou-se o "possível" futuro das apanhadoras de café do município.

Ressalta-se que esse trabalho, que é fruto de um projeto de iniciação científica (PIBIC/FAPEMIG), teve como embasamento teórico sobre os temas geografia e questão de gênero, trabalho feminino na agricultura e na cafeicultura, os autores Francisco (2011), Bombardi (2004), Martins (1979), BARROS et al., (2014), Silva et al. (2010) e Rossini (2002). Os dados secundários foram coletados junto à Prefeitura Municipal e Sindicato dos Trabalhadores Rurais de Divisa Nova e site do IBGE, e os primários, por meio de entrevistas com o presidente do sindicato e com mulheres do município, que trabalhavam ou trabalham em colheitas nas lavouras cafeeiras, com faixa etária diversificada (entre 21 e 74 anos). Ressalta-se que do total das mulheres entrevistadas, $40 \%$ ainda trabalham na colheita de café, $25 \%$ já são aposentadas, $15 \%$ são aposentadas e ainda trabalham como apanhadoras de café e $20 \%$ delas trabalham em outras atividades empregatícias no espaço.

Assim, o trabalho se estrutura, tomando como ponto de partida a discussão sobre questão de gênero na Geografia Agrária, para depois explicar as relações de trabalho na cafeicultura no município de Divisa Nova e contextualizar a situação das apanhadoras de café aposentadas e das ativas.

\section{O GÊNERO NA GEOGRAFIA AGRÁRIA: O TRABALHO RURAL FEMININO}

Estudos de gênero na Geografia em espaços rurais iniciaram-se, no Brasil, somente entre as décadas de 1970 e 1980 - tardiamente, se comparada com outros países, como Inglaterra e Espanha -, a partir de análises da "divisão de trabalho por 
gênero e idade e as relações de poder dentro da unidade doméstica". Antes deste contexto, discussões teóricas metodológicas ligadas ao gênero, sobretudo à espacialidade da mulher do campo, eram marginalizadas nos estudos geográficos (FRANCISCO, 2011 p.32). Dessa forma, será através do gênero na Geografia que o papel ativo feminino no campo será contextualizado no espaço geográfico, retratando a mulher como ator social, responsável por atividades produtivas e reprodutivas.

No espaço agrário brasileiro, as mulheres foram incluídas em atividades relacionadas ao campo a partir do colonato. Todos os integrantes da família trabalhavam em terras de fazendeiros em troca de moradia e subsistência. O pai como figura patriarcal era o responsável pelo recebimento e administração do salário ou ganho recebido. Mulheres e crianças eram vistos apenas como ajudantes, responsáveis por cuidados com plantações em terras que eram doadas para o sustento familiar e atividades domésticas (MARTINS, 1979, p.19).

Todavia, o trabalho feminino dentro de uma unidade familiar ou como mão de obra assalariada é tido como invisível ou como uma mera ajuda (BOMBARDI, 2004). Diante dessa invisibilidade feminina no trabalho rural, muitas mulheres acabam migrando para as cidades em busca de uma renda própria e liberdade para administrála da forma que bem entender, pelo menos aparentemente. E talvez seja por conta disso, aliado à vivência em espaços urbanos que dificultam o seu retorno ao campo (BARROS et. al., 2014, p. 719).

Tal situação não impede, no entanto, que cada vez mais as mulheres atuem em atividades agrícolas como trabalhadora rural, assalariada e autônoma, participando diretamente da renda familiar, a partir de sua remuneração, exercendo atividades nos cafezais, laranjais, canaviais, entre outras culturas agrícolas (SILVA et. al., 2010). Esse salário também tem permitido, mesmo residindo no espaço rural, que essas mulheres incorporarem hábitos de consumo urbanos, acessando novas formas de tecnologias da comunicação e da informação (TV a cabo, internet), de serviços públicos e políticas governamentais.

O acesso a estes bens e serviços materiais e culturais reflete-se no seu estilo de vida, nas suas condições materiais de vida, tal como no seu padrão de moradia, no tempo gasto para realizar as suas atividades domésticas e 'produtivas', bem como nas suas formas e possibilidades de lazer (RAMBAUD, 1969, apud BARROS et al., 2014, p. 720-721).

Em seus estudos Rossini (2002, p.52) levanta uma questão importante acerca das mudanças que promoveram o crescimento da mão de obra feminina no mercado de trabalho que se baseiam em mudanças socioeconômicas, demográficas e culturais, como a queda de fecundidade, a escolarização feminina, mudanças nos arranjos familiares e inserção de políticas públicas.

\section{RELAÇõES DE TRABALHO E CAFEICULTURA NO MUNICÍPIO DE DIVISA NOVA}

O município de Divisa Nova integra a microrregião de Alfenas (Figura 1). De clima temperado e relevo levemente acidentado, se insere na terceira fase da expansão da cafeicultura da mesorregião Sul/Sudoeste de Minas, relacionando-se à expansão do meio técnico científico informacional no espaço rural e a criação de um novo modelo espacial para a produção do café iniciada na década de 1970, a partir de uma agricultura mecanizada, poupadora de mão de obra (VILELA; RUFINO, 2010, p. 9). 


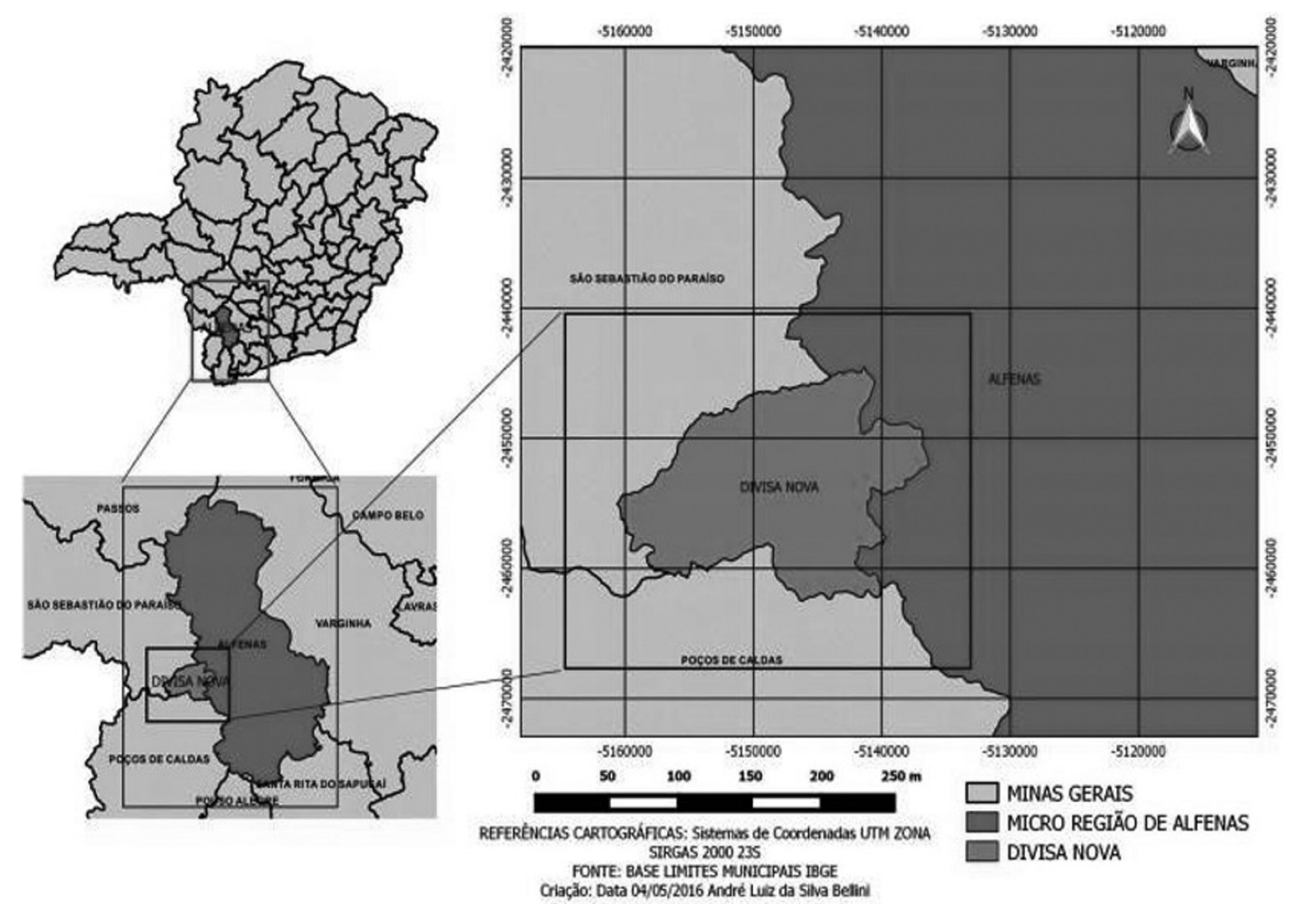

Figura 1 - Localização do município de Divisa Nova na Microrregião de Alfenas-MG

Fonte: IBGE - Base cartográfica digital.

Essa expansão cafeeira, praticada em moldes modernos e em grandes propriedades, contribuiu para o aumento do grau de urbanização, que vem se acentuando desde a década de 1980 , atingindo aproximadamente $81 \%$ da população total, em 2010, segundo o Censo Demográfico do IBGE (gráfico 1). Todavia, num município tão pequeno - estimativa de 6.050 habitantes (IBGE, 2016) - a cidade não é capaz de gerar empregos suficientes para seus moradores, contribuindo para o aumento dos problemas sociais.

8.000

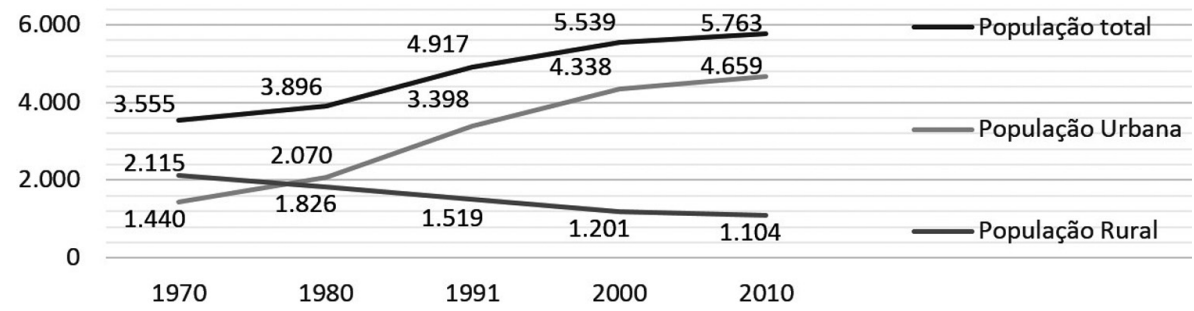

Figura 2 - Gráfico da População rural, urbana e total do município de Divisa Nova/MG (2010)

Fonte: SIDRA/ IBGE (2010). 
A história de formação territorial de Divisa Nova está relacionada às questões rurais, originando-se a partir da doação de quarenta alqueires de terra em 1860, pelo capitão Silvério Luís de Figueiredo, formando assim, o povoado de São João da Boa Vista, em homenagem ao santo padroeiro local. Em 1923, o distrito teve o seu nome modificado para Divisa Nova, por possuir sua localização territorial entre duas fazendas. O distrito foi elevado à categoria de município em 1938 (IBGE, 2016). Conforme já mencionado, o trabalho sazonal agrícola mais significativo no município ocorre no período da colheita de café, com contratações de trabalhadores que são conhecidos como apanhadores de café. Em unidades de produção familiar os membros da família e vizinhos, costumam trabalhar na colheita, por trocas de dias de trabalho, contratando trabalhadores assalariados, somente quando não há essa possibilidade.

Nas propriedades, onde a colheita de café ainda é executada de forma manual em Divisa Nova, esses trabalhadores costumam residir na sede do município e se deslocar diariamente para as áreas rurais, durante todo o período da colheita de café. Dessa forma, o comércio e o modo de vida da população são organizados entre a sazonalidade do período de safra da cafeicultura.

\section{AS APANHADORAS DE CAFÉ DE ONTEM E DE HOJE}

As mulheres sempre estiveram presentes nas colheitas de café no município, desde o colonato, antes mesmo da atividade agrícola se tornar uma prática remunerada e individualizada, como relata uma das entrevistadas:

Cada família tinha sua empreita na fazenda, a quantidade de café que cuidava até a colheita. Era um salário por família. Minha mãe ajudava na lavoura e trabalhava em casa. Eu e minhas irmãs ajudava na lavoura. Gostava de trabalhar lá. Tinha que gostar. Era o único serviço que tinha (M.C.R., 52 anos).

A grande maioria das mulheres entrevistadas (80\%) afirmou gostar do trabaIho na colheita de café (Figuras 2 e 3) e o motivo principal seria a socialização que essa atividade permite, já que é o momento em que podem conversar com outros (as) trabalhadores (as). Seria, segundo elas, uma forma de se "livrarem", ainda que por um tempo, da rotina de afazeres domésticos e, até mesmo, de esquecerem-se de problemas pessoais e de enfermidades. Nesses relatos, isso fica evidente, tanto para as aposentadas quanto para trabalhadoras ativas, quando questionadas sobre sua satisfação no trabalho nos cafezais: 1) "Eu gostava de apanhar café. Parece que esquecia até das doenças, esquecia de tudo. Não achava ruim não, eu gostava muito" (M. A., 74 anos); 2) "Serviço de casa enjoa. Nossa, eu amo ir para a roça. A gente parece que "desparece" muitas coisas, concentra ali e esquece de tudo, a gente conversa, trabalha com o pessoal né? Muito bom" (M. L. S. P. T, 56 anos). No entanto, para ao restante das entrevistadas (20\%), esse tipo de trabalho é considerado como muito cansativo, já que requer muito esforço físico (Figura 4), fato que as tem levado a buscar por outras atividades no espaço urbano do município. 


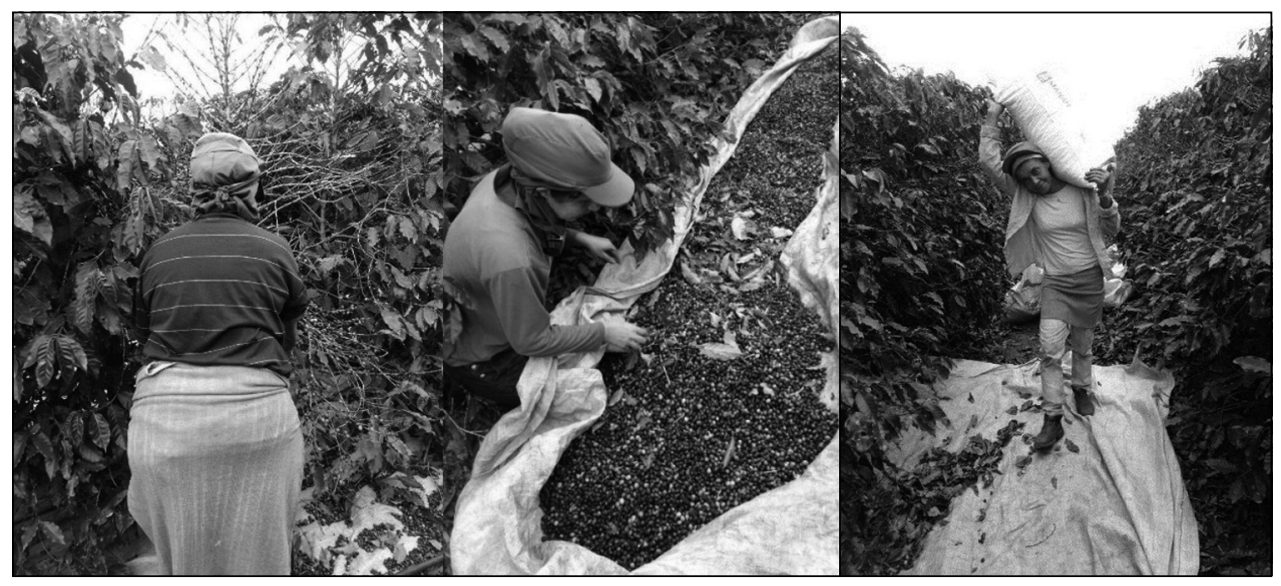

Figura 3 - Mulheres trabalhando na colheita de café na Fazenda Santa Clara, no município de Divisa Nova- MG

Fonte: Trabalho de campo, junho/2016.

O trabalho sazonal no café em Divisa Nova possibilita às mulheres, principalmente as casadas, a participação no acerto de dívidas e de necessidades ligados a casa e a família. As trabalhadoras entrevistadas alegaram que é somente no período da colheita de café que podem participar de forma significativa no orçamento doméstico. O salário permite que elas contribuam, por exemplo, em reformas na casa, compras no supermercado, de novos utensílios e móveis e ainda cooperar em cuidados e gastos com os filhos. Quando questionadas sobre o destino dado ao salário recebido pela colheita, as respostas dessas duas trabalhadoras confirmam a importância dessa remuneração para a renda familiar: 1) "Eu já comprei colchão, já dei o dinheiro pro Joel (marido da entrevistada) comprar o material da casa, ajudei a pagar o terreno da casa e comprei umas coisas para as crianças e pra mim também" (A. F. L., 32 anos); 2) "Compro roupa de cama, faço estoque de alimentação para o ano, a gente paga a compra lá no mercado, e deixa as coisas lá e vai pegando aos poucos. Já comprei móveis com o dinheiro, da apanha e também já paguei o imposto da casa" (M. C. R., 52 anos).

De acordo com as mulheres entrevistadas, regulamentações trabalhistas no campo promoveram grandes mudanças no trabalho rural, principalmente na colheita de café, propiciando melhorias nas condições de trabalho e igualando-o ao masculino. A inserção de banheiros químicos, de EPI (Equipamento de Proteção Individual), de transportes seguros e um horário estabelecido para o término da jornada de trabalho, assim como o registro em carteira, pagamento de FGTS (Fundo de Garantia por Tempo de Serviço) e a aposentadoria, são conquistas apontadas por elas como favoráveis.

Esses depoimentos de três apanhadoras aposentadas evidenciam essa satisfação: 1) "A mudança das leis, apesar de não ser a muito tempo, permitiu que os homens e as mulheres tivessem os mesmos direitos trabalhistas na apanha" (A.B.S., 50 anos); 2) "Antigamente era muito difícil, ia trabalhar em caminhão, ia a pé, não tinha banheiro... hoje tudo melhorou" (S. R. S. 71 anos); 3) "Antigamente eu não dava equipamento de proteção, num dava nada, hoje eles dão bota, óculos, luva, chapéu... Antigamente a gente ia de caminhão, de carreta, agora hoje é ônibus tem tudo, tudo no seguro e antigamente não tinha nada" (V. F. S., 74 anos). Da mesma 
forma pensam as que continuam trabalhando nos cafezais: 1) "Agora tem mais segurança no trabalho, antigamente era tudo mais largado, cada um por si, hoje tem os equipamentos de proteção que eles são obrigados a dar" (P. R. S., 21 anos); 2) "A carteira assinada ajudou muito! Hoje temos direitos a fundo de garantia e a acertos depois da apanha" (M.C. R., 52 anos).

Apesar das mudanças legislativas do trabalho no campo e as melhorias nas condições de trabalho na colheita de café, tem crescido a busca de trabalhadoras rurais por empregos em atividades urbanas, em Divisa Nova, considerados, por algumas das entrevistadas, como sendo trabalho mais leve e melhor remunerado. Na realidade, houve, entre 2000 e 2010, uma queda na participação na população ativa do município nas atividades agropecuárias, sendo que a masculina reduziu de $72,9 \%$ para $67 \%$ e a feminina de $56,1 \%$ para $46,9 \%$. Por outro lado, na atividade industrial, houve um crescimento da mão de obra, mas dessa vez muito sutil na masculina, subindo de $11 \%$ para $11,2 \%$, enquanto, na feminina mais que dobrou indo de $2,4 \%$ para 5,8\% (IBGE, 2000 e 2010). Um dos motivos para esse aumento feminino no emprego urbano deve-se ao fato de que foram instaladas na cidade algumas indústrias de confecções (lingeries, camisetas, enxovais de bebê, calças jeans), no período apontado acima, que comumente contrata mais mulheres do que homens. Um exemplo é uma cooperativa de mulheres que confecciona roupas e enxovais de bebês, administradas por antigas apanhadoras de café do município (Figura 5), que conta com a atuação de seis mulheres ex-apanhadoras de café. A empresa foi criada em 2014, por mulheres que possuem faixa etária entre 20 a 30 anos.

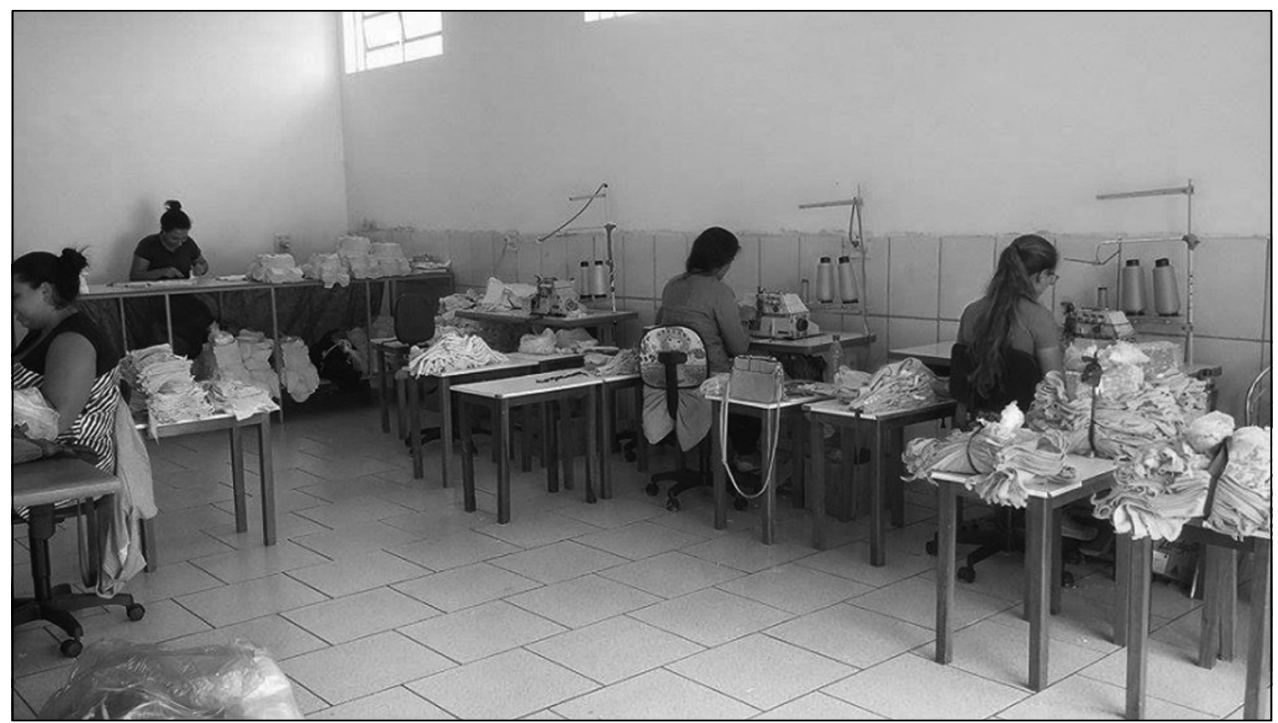

Figura 4 -Mulheres trabalhando em fábrica de confecção de roupas e enxovais de bebês, em Divisa Nova/MG

Fonte: Trabalho de campo, fevereiro/2017.

Em entrevista, duas associadas à cooperativa explicaram os motivos pelos quais preferem trabalhar nessa atividade em detrimento do agrícola: 1) "Eu optei por mudar de trabalho para ter uma vida melhor para a gente, um futuro melhor 
daqui para frente. Ainda mais nós que abrimos uma empresa nossa, está empregando mais gente e está fazendo algo melhor" (A. R. B., 25 anos); 2) "O serviço sofrido, o sol, a chuva, as condições de trabalho difíceis na lavoura me fizeram a começar a procurar serviço na cidade, para crescer também, porque se eu ficar na lavoura eu vou ficar só naquilo, sem perspectiva alguma, principalmente para a gente que é mais nova" (V. S.R., 24 anos).

Além da indústria, muitas mulheres que abandonam o trabalho na lavoura de café, optam por se dedicarem a trabalhos urbanos, como o de empregada domésticas ou em serviços gerais, tanto em Divisa Nova como em cidades vizinha, como Alfenas. Esse é caso dessa entrevistada: "Na panha de café ganha mais, mas sofre mais. E depois que acaba a panha, cê corre o risco de ficar sem serviço o resto do ano, daí eu decidi trabalhar direto em casa de família" (A. F. V. C., 42 anos).

Há também casos de apanhadoras de café mais jovens que acreditam que o trabalho urbano pode ser uma oportunidade de continuar os estudos: "Minha intenção não é "panhar" café mais não, pelo menos por enquanto. Eu quero arrumar outro emprego, de preferência aqui na cidade, quero estudar, quero fazer Psicologia" (P. R. S., 21 anos). Ela acredita que o trabalho na lavoura não Ihe trará oportunidade para a realização desse sonho, pois seria vencida pelo cansaço diário e chegaria muito tarde para se arrumar, pegar o ônibus de estudantes e ir para a faculdade em Alfenas - 25 km distante de Divisa Nova -, onde existem duas universidades: UNIFAL-MG (pública) e UNIFENAS (particular).

A mecanização da colheita do café também foi apontada pelas entrevistadas com um dos motivos de desistirem desse tipo de trabalho. Na realidade, as apanhadoras de café não costumam exercer atividades mecanizadas, sejam maquinários de grande porte ou manuais, sendo essa uma tarefa preferencialmente masculina. A mulher quando inclusa nesta atividade, é vista apenas como ajudante do marido ou companheiro, que manobra a colheitadeira manual, cabendo a ela a responsabilidade de estender o pano para colocar o café colhido, antes de ser ensacado. Segundo uma dessas trabalhadoras, "a mulher ajuda o marido a limpar o pano, mas nunca manuseia a maquininha de colher café" (P. R. S., 21 anos).

A diminuição de contratações femininas na colheita de café no município também se explica pelo preconceito, que ainda acompanha as trabalhadoras em nosso país, cujos empregadores ainda veem na maternidade um empecilho para sua contratação. Isso fica bastante claro na fala presidente do Sindicato dos Trabalhadores Rurais de Divisa Nova, que também é fiscal de colheita de café em uma fazenda do município:

[...] a mulher que tem filho às vezes precisa ficar falhando e se falha demais, prejudica na produção, lá (fazenda onde fiscaliza) é mais é homem mesmo. Lá os homens trabalham com a maquininha e com o maquinário pesado. Nem solteira eles empregam. É muito difícil. Poucas mulheres que vai. Durante a "panha" vai trabalhar, no muito, 5 mulheres, numa turma de 28 pessoas (SANTOS, 2016).

Apesar da discriminação e da falta de reconhecimento ao trabalho exercido na lavoura, existem entre um grupo entre entrevistadas que pretendem continuar na atividade, sobretudo pela falta de oportunidade e avanço na idade para se inserirem em outras formas de trabalho, justificada pela falta de estudo ou por faltar pouco tempo para se aposentarem. Esses depoimentos mostram esse posicionamento delas: 1) "Eu não pretendo mudar de serviço não. Tenho 47 anos já e está mais perto para eu aposentar. Se eu mudar de serviço agora, fica mais difícil, né? Só falta mais 5 anos, dá para aguentar. Não compensa mudar (T. R. P., 47 anos); 2) "A gente tem muita pouca escolha. Eu gosto do que eu faço. E tem mais, a gente está mais de idade 
e também hoje eles tão exigindo muito estudo, e isso a gente não tem. A gente estudou quase nada, quando nós era pequeno. As coisas eram mais difícil" (M. A. P., 58 anos); 3) "Eu estou trabalhando de babá, sabe? Mas acho que vou voltar para a apanha, por causa do registro na carteira, porque senão na hora que for aposentar fica mais difícil (A. F. L., 32 anos).

\section{CONSIDERAÇÕES FINAIS}

A partir dos relatos das apanhadoras de café de Divisa Nova, foi possível constatar que elas sempre tiveram um papel muito na cafeicultura do município. Para as trabalhadoras mais velhas, as conquistas vindas por meio de legislações trabalhistas, trouxeram melhorias no trabalho e, de certa forma, as igualaram ao dos homens. E, embora muitas vezes seja penoso, esse tipo de trabalho representa uma forma de socialização e de certa autonomia financeira, ou pelo menos, de participação na renda familiar. A falta de escolarização também as possibilita de buscar alternativas de emprego.

Por outro, lado, as trabalhadoras mais jovens, têm preferido se dedicar a atividades urbanas, nas quais afirmam encontrar condições de trabalhos mais amenas e favoráveis em termos financeiros. No entanto, é preciso considerar que a grande maioria esses trabalhos urbanos, podem não lhes dar essas garantias trabalhistas encontradas na colheita de café. Mesmo assim, influenciadas pela urbanização, acreditam que no espaço urbano encontrarão oportunidades para crescerem profissionalmente e realizarem os seus projetos de vida. Diante desse quadro, pode-se apontar que o futuro seja de participação cada vez menor de mulheres nas colheitas de café em Divisa Nova, mas não abandono total, pois essa é uma atividade tradicional, que diante da falta de opção urbana num pequeno município, acaba por atrair trabalhadoras nas épocas de colheita, sobretudo as com baixo grau de escolaridade, independente da faixa etária.

\section{REFERÊNCIAS}

BARros, V. M. A.; FIÚZA, A. L. C.; SIlVEIRA, L. N.; PEREIRA, G. A. Os efeitos do trabalho sazonal das mulheres na colheita do café em um campo em transformação. Campo Território: revista de geografia agrária, v. 9, n.17, p. 715- 734, abr., 2014, p. 717 -721. Disponível em: http://www.seer.ufu.br/index. php/campoterritorio/article/ view/23082>. Acesso em: 06 de agosto de 2016.

BOMBARDI, L. M. O Bairro Reforma Agrária e o processo de territorialização camponesa. São Paulo: Annablume, 2004.

FRANCISCO, O. L. M. de. Geografia de Gênero e Trabalho Familiar: Algumas considerações. Revista Latino Americano de Geografia, v.2, n.1, jan.-jun./ 2011p. 27-36. Disponível em: http://www.revistas2. uepg.br/index.php/rlagg/article/view/ 1745. Acessado em: 20 de agosto de 2016.

IBGE Cidades. Disponível em: http://cidades.ibge.gov.br/xtras/perfil.php? codmun $=312240>$. Acesso em: 30 de janeiro de 2016 . 
IBGE. Produção Agrícola Municipal - Disponível- site IBGE (22 maio 2016). URL: http://www.sidra.ibge.gov.br/bda/tabela/protabl.asp?c $=74 \& z=t \& o=4 \& i=P$. Acessado em: 22 de maio de 2016.

IBGE. Sistema IBGE de Recuperação Automática - SIDRA. Disponível: site. http:/ /www.sidra.ibge.gov.br/bda/tabela/protabl.asp?c $=200 \& z=c d \& o=2 \& i=P$. Acessado em: 22 de maio de 2016.

MARTINS, S. de, M. O cativeiro da Terra. São Paulo: Livraria Editora Ciências Humanas 1979.

PREFEITURA MUNICIPAL DE DIVISA NOVA. Disponível em: http:// www.divisanova.mg.gov.br/principal.asp. Acesso em: 09 de fevereiro de 2017.

SANTOS, I. Entrevista concedida à RAIMUNDO, Glaucione. Divisa Nova, 04 de dezembro de 2016.

SILVA, J. M. Geografia e Gênero no Brasil: uma análise da feminização do campo científico. Ateliê Geográfico - Revista Eletrônica. UFG, set. 2010, p. 38- 62. Disponível em: http://www.revistas.ufg.br/index.php/atelie/article/view/7333. Acesso em: 11 out. 2015.

ROSSINI, R. E. Nas atividades econômicas a modernidade tecnológica exclui homens e mulheres. Incorpora mais a mulher na cidade e menos no campo. Revista Geousp - Espaço e Tempo. São Paulo, n 12, ano 2002. p. 47-56.

VILELA, P. S.; RUFINO, J. L. S. (Org.) Caracterização da Cafeicultura de Montanha de Minas Gerais. Belo Horizonte: INAES, 2010 (Estudos INAES. Cadeias Produtivas. Disponívelem: <http://www.inaes.org.br/publica/Livro_cafeicultura_de_montanha.pd>. Acessado em: 08 de fevereiro de 2017. 